\title{
ASPECTES DE LA TRANSITIVITAT EN ELS INICIS DEL CATALÀ MODERN*
}

\author{
ASPECTS OF TRANSITIVITY \\ AT THE BEGINNING OF MODERN CATALAN
}

\author{
Anna Pineda \\ Universitat Pompeu Fabra \\ anna.pineda@upf.edu
}

Resum: En aquest estudi de corpus hem volgut fer una primera aproximació a diversos aspectes de la transitivitat, entesa com a fenomen amb diversos vessants, en els textos corresponents a l'inici del català modern (segle Xviı, amb un èmfasi especial en la primera meitat de segle). Hem tractat, concretament, el cas de diversos verbs que presenten un comportament vacil.lant entre l'ús transitiu i l'ús intransitiu, i ens hem acostat a aquest fenomen des del vessant del marcatge diferencial d'objecte, atès que aquest règim vacil-lant és un factor que pot crear confusió a l'hora d'analitzar l'extensió dels objectes directes introduïts per $a(v . \$ 2)$. A continuació, i encara mantenint el marcatge diferencial d'objecte com a punt de referència, ens hem fixat en les diverses construccions que afavoreixen notablement l'ús d'aquest marcatge davant dels objectes directes (v. \$3). Per acabar, hem tractat de manera succinta altres aspectes interessants de la transitivitat en els textos dels inicis del català modern, com ara l'ús de verbs inergatius en patrons transitius que inclouen un objecte directe cognat o la causativització de verbs intransitius que expressen moviment (v. \$4).

Paraules clau: transitivitat, marcatge diferencial d'objecte, alternança transitiu/intransitiu, alternança acusatiu/datiu, objectes cognats, causativització, català modern.

$\left(^{*}\right)$ Aquest treball ha rebut el suport de l'ajut postdoctoral Juan de la Cierva-incorporación (IJCI-20I630474, Ministerio de Economía y Competitividad) i del projecte de recerca FFI20I4-56968-C4-I-P (Ministerio de Economía y Competitividad). 
Anna Pineda

Aspectes de la transitivitat en els inicis del català modern

Abstract: In this corpus study we make a first approach to different aspects of transitivity, understood as a phenomenon with multiple faces, in the texts corresponding to the beginning of Modern Catalan (I7th century, with a especial emphasis on the first half of the century). In particular, we deal with the case of several verbs showing an hesitating behaviour between the transitive and the intransitive use, and we undertake the study of this aspect from the point of view of differential object marking, since the alternations in these verbs may be confusing when analysing the pervasiveness of direct object introduced by $a$ (see $\$ 2$ ). Next, also taking differential object marking as the reference point, we focus on the constructions that favour significantly the use of this marking in front of direct objects (see $\$ 3$ ). Finally, we briefly deal with some other interesting aspects of transitivity in the texts of the beginning of Modern Catalan, such as the use of unergative verbs in transitive patterns including a cognate direct object, or the causativization of intransitive verbs of motion (see $\$ 4$ ).

Key words: transitivity, differential object marking, transitive/intransitive alternation, accusative/ dative alternation, cognate objects, causativization Modern Catalan.

\section{$\operatorname{cosect}$}

\section{INTRODUCCIÓ}

En aquest article ens ocupem de diversos aspectes de la transitivitat en la llengua catalana de l'inici de l'etapa moderna, concretament del segle xviI. Estudiem, més particularment, el marcatge diferencial d'objecte (mDo d'ara endavant), és a dir, l'ús de la preposició a davant d'un objecte directe, des de l'angle del tipus de verb (v. \$2) i del tipus de construcció (v. $\$ 3$ ). Aquest treball és, doncs, complementari al que presentàvem en Pineda (en premsa), en què analitzàvem el MDo tenint en compte les característiques semàntiques (en els eixos de definitud i d'animacitat) de l'objecte directe. Més enllà del MDo, complementem l'article amb un apartat en el qual esmentem breument alguns altres aspectes interessants relacionats amb la transitivitat en aquesta etapa de la llengua moderna (v. $\$ 4$ ). Finalment, cloem el treball amb les conclusions (v. $\$ 5$ ).

En estudiar el que ocorre al segle Xvir pretenem, de fet, complementar en l'eix temporal referit al català modern l'estudi de Pineda (en prep.) sobre el període del català antic (segles XIII-XVI). Així, volem constatar si els verbs que al llarg del període anterior presentaven un comportament variable pel que fa a la transitivitat, com ara ajudar o pregar, ja s'han assentat en un determinat règim, o bé encara mantenen aquella inestabilitat que podia crear confusió a l'hora de determinar si un complement 
introduït per $a$ és un objecte directe d'un verb transitiu o bé un objecte indirecte d'un verb intransitiu. A això dedicarem l'apartat $\$ 2$.

Semblantment, aquesta visió de continuïtat respecte de l'estudi de Pineda (en prep.) també regeix l'anàlisi que fem de com el MDO es pot veure afavorit per diversos factors relacionats amb el tipus de construcció, com ara la dislocació i altres qüestions d'ordre de mots, la coordinació de sintagmes de diferent tipus, els contextos causatius, la presència d'un complement predicatiu referit a l'objecte directe, els paral-lelismes o les comparacions amb elisió del verb, entre d'altres. A tall d'exemple, si la posició dislocada d'un objecte directe fou des dels inicis un context força favorable a la presència del MDo (Pineda en prep.), veurem ara si, al cap dels segles, encara suposa un tret diferencial quant a la freqüència d'aparició del marcatge. De tot això en parlarem a l'apartat $\$ 3$.

Com avançàvem, en aquest estudi de corpus posem el focus en el segle XVII, concretament en la primera meitat, amb una selecció de textos representatius de la variació dialectal i, concretament, de la divisió en dos blocs, occidental i oriental. Sempre que ha estat possible, s'ha estudiat el conjunt de les primeres I5 000 paraules de cada text, tret dels casos en què el document de què disposàvem tenia un nombre inferior de paraules. Ho resumim en la taula següent:

\begin{tabular}{|l|l|l|}
\hline Text & Dialecte & Fragment analitzat \\
\hline Dietari de P. J. Porcar & occidental valencià & I5 000 primers mots \\
\hline El 'Libre de Antiquitats' de la Seu de València 4 & occidental valencià & I5 000 primers mots \\
\hline Un memorial de la guerra contra el turc 5 & oriental baleàric & text íntegre (800 mots) \\
\hline Viatge a l'infern d'en Pere Portés & oriental central & text íntegre (9000 mots) \\
\hline Dietari de J. Pujades & oriental central & I5 000 primers mots \\
\hline
\end{tabular}

Taula I. Corpus estudiat corresponent a la primera meitat del segle XvII

Aquest és el mateix corpus emprat en Pineda (en premsa), treball que, com dèiem, és complementari al que ara presentem. Precisament, en Pineda (en premsa) constatàvem que els parlars valencians eren especialment interessants pel que fa a l'extensió i sistematització del MDO, i per aquesta raó optàvem per resseguir el comportament d'aquests dialectes en dos textos més, ara de la segona meitat del segle Xvir. Per tal de mantenir el paral.lelisme, en aquest treball tindrem també en compte les dades provinents d'aquests dos textos més de l'àrea valenciana —encara que amb una diferència: mentre que en Pineda (en premsa), on s'estudia l'extensió del MDo segons les característiques semàntiques, era significatiu fer la diferència 
Anna Pineda

Aspectes de la transitivitat en els inicis del català modern

entre els textos pertanyents a una taula i a l'altra, aquí els tractem tots de manera unitària, perquè en l'estudi dels aspectes que s'analitzen tal distinció temporal no és substancialment rellevant: ${ }^{1}$

\begin{tabular}{|l|l|l|}
\hline Text & Dialecte & Fragment analitzat \\
\hline Dietari d'Aierdi & occidental valencià & I5 000 primers mots \\
\hline El 'Libre de Antiquitats' de la Seu de València 5 & occidental valencià & text íntegre (5000 mots) \\
\hline
\end{tabular}

Taula 2. Corpus estudiat corresponent a la segona meitat del segle XVII

Així mateix, convé fer constar que en l'apartat $\$ 2$, dedicat a l'estudi qualitatiu i detingut d'un grup de verbs en concret, sovint hem optat per fer cerques selectives més enllà del límit de 15000 paraules establert, per tal d'obtenir una fotografia més acurada i més ben fonamentada del funcionament d'un verb concret en un text determinat. En canvi, per a la resta d'apartats de l'article, igual que ocorria en Pineda (en premsa), l'estudi s'ha cenyit en general al límit de mots establert a les taules, am l'objectiu de fer un tractament de les dades més quantitatiu.

No cal dir que l'estudi que presentem és només un primer acostament a aquests aspectes de la transitivitat, que se centra en un període volgudament acotat, els inicis del català modern, i presenta també una proporció major de textos d'una àrea concreta, la valenciana. Sens dubte, caldrà completar aquest acostament amb un estudi de corpus que tingui en compte la resta del període temporal del català modern i que es basi en textos de procedència dialectal i de tipologia diversa.

\section{VERBS DETRANSITIVITAT VARIABLE: INFLUÈNCIA EN EL MARCATGE DIFERENCIAL D’OBJECTE}

Són diversos els verbs catalans que presenten variabilitat quant a la possibilitat de construir-se com a transitius o com a intransitius, la qual cosa es tradueix en una alternança de cas acusatiu/datiu en el seu complement (per a un tractament exhaustiu d'aquest fenomen en la llengua actual, v. Pineda 20I5 i 20I6: \$ 5). Sovint, l'origen

I. Com que tots els exemples citats pertanyen al mateix segle, i com que aquestes dues taules explicitem si pertanyen a la primera meitat de segle o a la segona, hem considerat prescindible repetir cada vegada l'especificació de l'any de cada obra. Aquesta informació es troba al final de l'article, on donem la referència completa de totes les obres del corpus estudiat. Així mateix, per indicar la font dels exemples, ens servim de la clau de citació de cada obra. De nou, el títol sencer i tota la informació de cada obra es poden trobar al final de l'article. 
d'aquesta variació es troba en les etapes precedents de la llengua. Si en Pineda (en prep.) analitzem aquest fenomen en relació amb el català antic, aquí dediquem aquest apartat a analitzar-lo en el context de l'inici del català modern.

\section{I AJUDAR}

La inestabilitat del verb ajudar pel que fa a la distinció transitiu/intransitiu és prou reconeguda (v., per exemple, DCVB s.v. ajudar; Solà 1994: 174-175; Ramos 2005: IOI; Morant 2008: 209-234, i Pineda 20I6: \$ 5.2.5). De fet, d'això la llengua antiga en dona nombrosos testimonis (Pineda en prep).

En el corpus estudiat, aquest verb apareix només en dos textos. En un cas, en tenim tres ocurrències que apunten clarament a un comportament transitiu del verb, atesa la construcció passiva — de fet, en la resta del text, més enllà del límit de mots estudiats, no n'hem trobat cap més ocurrència:

(I) a. Ý lo Jove li tornà a preguntar què era lo que tenia, ý ahont anava, que si ell lo pogués ajudar en res, que li digués sos treballs, que ell li valdria ý afavoriria. (Portés, p. 214)

b. Déu las ha dexadas del tot, però ab tot proveheix Déu que sigan ajudadas ý afavoridas de algunas personas, ý los trau de treballs (Portés, p. 2I4)

c. yo vós hé promès de ajudar-vos ý donar-vos concell ý trasa ab què fóseu ajudat ý remediat: (Portés, p. 217)

Cal fer notar que aquestes ocurrències pertanyen al català central. En canvi, en l'altre cas, corresponent a un text valencià, les ocurrències localitzades mostren discrepàncies: en (2) l'ús del participi, com si fos una passiva, indica l'ús transitiu del verb; en canvi, (3) mostra com el complement del verb és introduït per una preposició, que a priori tant podria correspondre al cas datiu com al MDO.

(2) matà a don Geroni Artés Albanell ý a sa muller, dońa Lluïsa de la Cerda, ajudat de un taverner dit Sebastià, (Porcar, «Dietari», fol. 9v)

(3) Ý de la gran pudor entrà primer un home, ý s'ofegava, ý entrà un altre per a ajudar ad aquell. (Porcar, «Dietari», fol. 4or)

Per aquest motiu, hem fet en el cas d'aquest text una cerca selectiva del verb ajudar més enllà del límit de mots establert. De nou, però, els exemples evidencien que el verb ajudar és emprat com a transitiu (4) i com a intransitiu (5). Al costat d'aquests exemples clars, en tenim d'altres que tant podrien correspondre a l'ús transitiu amb 
Anna Pineda

Aspectes de la transitivitat en els inicis del català modern

MDO com a l'ús intransitiu amb un objecte indirecte (6) —en l'exemple (b), el fet que tots no estigui duplicat per un clític podria ser un indici que es tracta d'un datiu; v. el contrast amb una ocurrència de tots en el mateix text com a objecte directe, duplicat: «Ý dit señor marqués se va riure ý.ls saludà a tots ab gran alegria» (fol. $72 \mathrm{r}$ ).

(4) a. Ý lo excel-lentísim señor patriarcha ó féu com a bon pastor. Déu lo conserve, que ajudat de sa prudèntia los posà en la sua presò, ý al capellà. (Porcar, «Dietari», fol. 96v)

b. Ý uns hòmens dels grahons de la Llonja Nova ó advertiren ý, ajudats de altres, lo feren abaxar de hallà dalt. (Porcar, «Dietari», fol. 528r)

(5) a. hallí ens llevaren la creu lo racional de Sent Pere, que.s dya Navarro, ý los Vicents, Batiste ý Alexandre ý Làzer, torcedor, li ajudaren. (Porcar, «Dietari», fol. 96v)

b. Ý la hú de aquells, anant darrer son amo per a ajudar-li, com acostumava, tornava lo cavall arrere (Porcar, «Dietari», fol. II4v)

c. Dijous, a 27 de octubre, penjaren a Joan Baptiste Martínez, corredor de orella, perquè havia contrafet los albarans de la ciutat [...]. Ý tostemps havia dit que Sans Cotanda los y havia ajudat a fer. (Porcar, «Dietari», fol. I46r) $)^{2}$

d. Ý dimats, a 3 de juliol, a les deu hores del matí lo portaren vestit de dol, lligat ab una cadira, a penjar. Ý portava la cara desfigurada ý unflada, com si se haguera offegat. Ý dien que ab una beguda li havien ajudat, perquè no descubrís. (Porcar, «Dietari», fol. I59r)

e. $Y$ a les dotse hores lo tornaren a ferrar ab grillons ý cadena ý tancat, ab guardes de vista, fins tant se declare valer-li la església. Déu li ajude. (Porcar, «Dietari», fol. 343r $)^{3}$

f. accabada la consecració del sanguis, conegueren, qui li ajudava, que [el mossèn] dia disbarats. (Porcar, «Dietari», fol. 536r)

(6) a. Dit diumenge, fonch nomenat per racional de la ciutat de València Geroni Bayarri, notari, que renuncià la art per ser-ó ý ajudava hallí al racional. Ý aprés fonch racional. (Porcar, «Dietari», fol. 202r)

b. Ý anava ab gran diligència ý vigilància, ajudanta totsý remediant-los. (Porcar, «Dietari», fol. 368v)

Concloem, doncs, que encara al segle XviI perdura de manera clara la variació en l'ús d'aquest verb, fins i tot dins d'un mateix text.

2. En aquesta oració el verb ajudar apareix combinat amb dos clítics: el clític datiu representa el complement d'aquest verb, mentre que el clític acusatiu correspon al complement del verb fer, que ha ascendit ( $l i$ havia ajudat a fer-los).

3. En canvi, en aquest altre exemple paral-lel, amb el referent plural, no podem determinar si el clític és acusatiu o datiu:

(i) \$Disapte, a I5 de dit, portaren per València tres galeres de galeots per a enbarcar. Déu los ajude. (Porcar, «Dietari», p.) 


\subsection{PERDONAR}

També perdonar és un verb amb règim alternant en la llengua antiga (v. DCVB s.v. perdona, i Pineda en prep). Tanmateix, en tot el corpus estudiat només n’hem trobat un exemple, que n'evidencia l'ús transitiu:

(7) Masot, saltechador de camins, perdonat per Madrit. (Aierdi, «Dietari», p. I77)

Per confirmar que, efectivament, en la gramàtica de l'autor d'aquesta obra s'havia consolidat la transitivitat del verb perdonar, hem fet una cerca selectiva d'aquest verb en la resta del text, més enllà del límit de mots recollits en l'estudi de corpus inicial. D'aquestes noves ocurrències, bona part mostren el comportament transitiu del verb (8), de manera que sembla que cal entendre els casos, aparentment dubtosos, de (9) com objectes directes amb MDO. Amb tot, hem trobat també un cas del verb perdonar coordinat amb un altre verb amb objecte indirecte, cosa que podria interpretar-se com a indici de la perduració del règim vacil.lant d'aquest verb (IO) —es tracta, però, d'una sola ocurrència, que a més és poc clara.

(8) a. después de haver-se'n anat Benet Vicent, bandoler, ab tots o els més de ses camarades, tres anys a Nàpols a servir al rey per a poder eixir de treball y quedar perdonats, (Aierdi, «Dietari», p. 272)

b. Dit dia havien de penchar a un home y el virrey el manà suspentre fins a lo altre dia, después de nostra Senyora. Y lo haguera perdonat, si no fóra per ser lo delicte tan grave com era el de haver robat una iglésia y fet altres robos y morts. (Aierdi, «Dietari», p.)

c. Este home ya estava perdonat, perquè el senyor arquebisbe, quant acabà de ser virrey, el remeté per sinch-sentes lliures (Aierdi, «Dietari», p. 342)

(9) a. A 23 de dits, acabant don Pedro Artés de ser justícia criminal, remeté y perdonà per composició a l'home que en I9 dels corrents matà en lo mercat a tal Iranso en una punyalada, (Aierdi, «Dietari», p. 28I)

b. lo virey volgué perdonar al lisenciado perquè la Huniversitat li féu una embaixada, pregant-lo-i. (Aierdi, «Dietari», p. 333)

c. perdonant a qualsevol, encara que fos còmplise en ell. (Aierdi, «Dietari», p.)

(Io) Y a l'instant soltaren al Ciurana, ab què calificaren la vellaqueria, pués tenint tan pochs dies avia feta una mort tan malament, y tan facilment $l i$ donaren llibertat y perdonaren. (Aierdi, «Dietari», p. 343) 
Anna Pineda

Aspectes de la transitivitat en els inicis del català modern

\subsection{PREGAR I SUPLICAR}

L’alternança acusatiu/datiu en el complement del verb pregar és pròpia també de la llengua antiga (v. $D C V B$ s.v. pregar), i de fet es recull al diccionari normatiu actual (v. DIEC2, s.v. pregar). Si l'alternança encara és present en la llengua d'avui, no és estrany que en el corpus estudiat, del segle XviI, en trobem exemples. De fet, la inestabilitat del verb queda palesa en el fet que fins i tot en una mateixa obra, concretament pertanyent a l'àrea del català central, hi trobem exemples de pregar tant en acusatiu (II) com en datiu (I2): ${ }^{45}$

(II) a. que ell ó faria; ý lo pregà molt li digués què tenia ý de què estaba trist, pensatiu ý enujat. (Portés, p. 215)

b. dit Pere Portés se.n anà a casa del Balle de Tordera, ý lo pregà en gran manera que, pues avia feta asistència en la execució [que] li avían feta en véndrer béns, fes plaer de asistir (Portés, p. 232)

(I2) a. Veyent asò alguns parents seus, se.l ne portaren en casa ý li digueren ý li pregaren molt se asossegàs; (Portés, p. 232)

b. los hé pregat que me dexasen anar a Massanet, (Portés, p. 215)

En el darrer exemple de (I2) hem optat per interpretar la manca de concordança com un indici que el clític no és acusatiu sinó datiu. En efecte, si ens fixem en totes les ocurrències del clític los combinat amb un participi en tot el text sencer, trobem un cas en què el clític és datiu i, com és predictible, no concorda (I3), i un cas on el clític és acusatiu i, com és predictible també, sí que hi concorda (I4). Amb tot, és cert que podria ser que la concordança participal amb clítics acusatius ja s'hagués començat a perdre (i.e. ja hagués començat a ser opcional), com sembla que mostra l'exemple (I5), també de la mateixa obra. Les dades no permeten, doncs, fer generalitzacions gaire concloents.

(I3) reconeixent-se dels mals ý danys que ell los havia causat, (Portés. p. 224)

4. També trobem exemples ambigus, a causa de la coincidència formal del clític acusatiu i datiu de tercera persona plural:

(i) ý que te alterat lo enteniment, los pregam, per llevar la opinió de la gent que.l ouen ý àn ohit, (Portés, p. 235)

5. Hem prescindit també dels usos ditransitius amb ambdós complements pronominalitzats, del tipus lo y pregà. 
(I4) ý diu que los ha vistos en lo infern ý à parlat ab ells (Portés. p. 234)

(is) Ý ell ne volgué guaudir ý víurer esplendidament, ý los [els béns] ha gastat esplèndidament (Portés. p. 225)

Malauradament, tractant-se d'un text especialment breu, ja s'havia inclòs sencer en el corpus inicial, de manera que no s'ha pogut procedir a una prospecció més ampliada d'aquest verb en concret. Així doncs, atesa la situació de variabilitat presentada a (II)-(I2) quant al comportament transitiu/intransitiu de pregar, esdevé impossible determinar si l'ocurrència següent, de la mateixa obra, és un exemple de MDO (un objecte directe amb marcatge preposicional) o bé correspon, simplement, a un objecte indirecte:

(I6) Dit Pere Portés pregà al Balle de Hostalrich que li fes plaer de venir (Portés, p. 233)

En tot el corpus estudiat, només trobem un altre exemple del verb pregar en un altre text, en concret corresponent a l'àrea valenciana:

(I7) Los parroquians y clero, que veren que la festa que tenien determinada y disposta no podia lloir-se, pregaren a l'il.lustre cabildo fos servit de dilatar la processó asta el dumenche següent (Aierdi, «Dietari», p. I86)

En aquest cas, el fet de no disposar de més exemples que ens permetin determinar el comportament d'aquest verb fa que no sigui possible decidir si és un cas de MDO o bé un objecte indirecte. Per això, hem ampliat la cerca més enllà del límit establert en el corpus inicial per a aquest text. Dels casos que hem trobat amb l'objecte pronominalitzat, tots presenten datiu. En donem dos exemples en (I8). ${ }^{6}$ Això ens inclina a interpretar com a datius els casos de sintagmes plens encapçalats per $a$ que hem trobat en aquesta cerca ampliada (I9) — i el cas de (I7), és clar:

(I8) a. li pregà frare Aguilar a dit don Phelip que, pués ell no estava en treball ni el buscaven a ell, que se estigués quedo y que no ixqués de la alqueria, (Aierdi, «Dietari», p. 203)

b. anant-se'n al palàcio del senyor arquebisbe. Y li pregà es servís de posar-se en lo coche $\mathrm{y}$ anar ahon estava esta chent $\mathrm{y}$, ab sa prudència, veure si podia apasiguar-los. (Aierdi, «Dietari», p. 307)

(19) a. sa santedat de Alexandre Seté concedí per a que tots los fels christians pregasen a nostre Senyor per lo felís estat de la santa mare Iglésia (Aierdi, «Dietari», p. 292)

6. Hem descartat els usos del clític de tercera persona plural els/los, que fa indestriable el datiu de l'acusatiu. 
Anna Pineda

Aspectes de la transitivitat en els inicis del català modern

b. Vent lo desatino tan gran, lo virrey pregà molt als mateixos del dia avans tornasen a eixir a posar-los en rahó (Aierdi, «Dietari», p. 306)

c. Esta processó fonch per a col-locar a nostra Senyora dels Desenparats en lo altar machor de la Seu, per a les rogatives dels dies següents, per a pregar a nostre Senyor donàs tot bon asert a sa machestat en lo govern que comensava (Aierdi, «Dietari», p. 356)

d. Elles comensaren a fer com qui pregava als porters y els oferiren trenta reals. (Aierdi, «Dietari», p. 37I)

Pel que fa a suplicar, en tot el corpus estudiat només n'hem trobat una ocurrència (20), pertanyent a l'àrea del català central. Tenint en compte la transitivitat variable d'aquest verb en el període precedent (Pineda en prep.), hem optat per ampliar la cerca més enllà del límit de mots establert, en tots els textos del corpus. En l'obra a la qual pertany (20) no n'hi havia cap altre exemple, però en altres obres del corpus, sí. Concretament, hem trobat tant usos del verb amb configuració acusativa clara (2I) com usos intransitius amb l'objecte datiu (22). De nou, aquesta variabilitat complica la interpretació dels altres exemples trobats (23), que tant podrien correspondre a un objecte directe amb MDO com a un objecte indirecte — podem aventurar, però, que tenint en compte (2I) també deuen ser casos d'objecte directe, ara amb MDO, els de $(23 a, b)$, atès que tots pertanyen a la mateixa obra, corresponent per cert al català central; semblantment, tenint en compte els casos de (22), podem suposar que (23e,f), del mateix text valencià, corresponen a objectes indirectes, on $a$ és marca de datiu: ${ }^{7}$

(20) ý dit Portés veyent lo que pasava, devant de moltas personas suplicà $a$ dits oficials que no li traguesen res de casa (Portés, p. 213)

(2I) Perquè havent jo de anar a Gerona per lo effecte que diré a 24, comanant-me al pare sant Dalmau Moner y suplicant-lo si tenia a bé que yo me trobàs en aquella jornada, pregàs al senyor me donàs salut. (Pujades, «Dietari», fol. I33v)

(22) a. Y així li supplicava es servís de que partisen lo camí, anant a Albatera, que ell per a tal dia baixaria sinse falta (Aierdi, «Dietari», p. 225)

b. Y entonses envià un recado ab molt rendiment al molt il.lustre cabildo, sede vacant, supplicant-li li admetés la renunciació del benifet que posehia en la Seu (Aierdi, «Dietari», p. 348)

c. el canonche que avia de dir la missa y el mestre de seremònies arbitraren que, en venir lo virrey, se li supplicàs manàs enviar soldats de la guarda per a que desenbarasasen aquell puesto y es quedasen allí ynpedint no es tornàs a omplir de chent. (Aierdi, «Dietari», p. 354)

7. Hem prescindit també dels usos ditransitius amb ambdós complements pronominalitzats, del tipus lo y suplicà. 
(23) a. Y que com aquells no poguessen ésser trets de la terra, supplicavan a sa excellència se servís no donar hi lloch. (Pujades, «Dietari», fol. I69v)

b. Y supplicant a sa excellència que... (Pujades, «Dietari», fol. 24I)

c. Per ço que diuhen que havia dit, estant ajustats los estaments, que suplicasen a $S a$ Magestad que mudasen de perlat ý estaria la terra assosegada. (Porcar, «Dietari», fol. 442v)

d. Ý lo vicari ý official general supplicà, eo envià a supplicar, als frares de Predicadors que los que tenien sermons per a l'endemà que no predicasen, perquè ell daria les rahons. (Porcar, «Dietari», fol. I6ov)

e. La Huniversitat supplicà a la insigne ciutat, com a patrona seua, es servís de fer la demostració que de sa part pogués. (Aierdi, «Dietari», p. 325)

f. Y com se trobava ya vell y acsidentat, no trobava qui li donàs lo diner, ab què per asò, y per ser persona molt remisa y encollida, li prengué lo cor y supplicà a sa magestat es servís admetre-li la renunciació (Aierdi, «Dietari», p. 422)

\subsection{SERVIR}

La variació entre l'ús transitiu i l'intransitiu en la diacronia del català també caracteritza el verb servir (v. per exemple $D C V B$, s.v. servir; en canvi, el diccionari normatiu n'estableix només l'ús transitiu en la llengua contemporània, v. DIEC2, s.v. servir). En el nostre estudi de corpus, trobem tant exemples indubtablement transitius (24), com casos on no podem tenir la seguretat de com interpretar el sintagma introduït per $a$, que tant podria ser un objecte directe amb MDo com un objecte indirecte $(25):^{9}$

8. En aquest exemple, s'interpreta que el referent del complement la ciutat és un col-lectiu d'individus, com es desprèn d'altres exemples diversos del text, com ara:

(i) Anaren totes les relichions y parròquies, el cabildo y clerecia de la Seu, el senyor arquebisbe, el virrey, la ciutat, lo governador, lo bal.le general, el mestre racional y demés officials reals, (Aierdi, «Dietari», p. 175)

9. Obviem els exemples del tipus (i), relacionats amb els de (ii). Prescindim també dels exemples de (iii) en què l'objecte no és animat, sinó que es refereix a l'ofici, treball o institució al qual es dona assistència i submissió:

(i) a. si és al cel, no necesita de cosa alguna; si en lo infern, no li aprofita res; ý si en lo purgatori, ell matex ne exirà quant Déu sia servit (Portés, p. 225)

b. Ý reclamant la favor del dit sant gloriós, fon servit nostre Señor, per intercessió del dit sant, que en sí dita señora sentís milloria ý ella es llevà de la dita cadira, (Porcar, «Dietari», fol. 48v) 
Anna Pineda

Aspectes de la transitivitat en els inicis del català modern

(24) a. ý que tots los que li dèyan mal home ý enganyador éran aquells que en vida lo serviren, (Portés, p. 224)

b. Y un hermità de Santa Magdalena de Montserrat anomenat fra Antoni, de nació portuguès, lo qual havia molts anys viscut en Barcelona servint les Elisabets, aprés les Repenedides y aprés les Descalças, ya suspecte de sodomita. (Pujades, «Dietari», fol. 53v)

c. Plàcia al Senyor sia a honra ý glòria sua, ý done perseverància que millor lo pugam servir. (Memorial V, p. IO2)

(25) a. ell los exortava que servisen a Déu N. Senyor, (Portés, p. 237)

b. y per veurer si podria servir al rey y exir de mal, assistí contra son germà y de mossur de la Bastida. (Pujades, «Dietari», fol. II)

c. Caygudes del món, de pobre cavaller jove praticant de notari en Barcelona, se n’anà a cort a servir al secretari Gassol, (Pujades, «Dietari», fol. 5Iv)

Atès que cap dels exemples anteriors presenta un clític datiu singular que permeti confirmar la combinació del verb servir amb un objecte indirecte, hom pot pensar que s'ha consolidat el règim acusatiu d'aquest verb (24), i que per tant els casos de (25) exemplifiquen l'ús del MDO. Amb l'objectiu de verificar aquesta hipòtesi, hem optat per ampliar la cerca d'aquest verb als textos sencers, més enllà del nombre de mots delimitat inicialment en el corpus. Només n'hem trobat exemples en tres obres ${ }^{10}$ però són prou abundants i ens permeten confirmar l'absència de casos de datiu indiscutibles (clítics). De nou, tenim casos que reflecteixen un ús transitiu clar (26) i d'altres que són dubtosos (27) perquè tant podrien correspondre a un objecte indirecte com a un objecte directe amb MDO — per hipòtesi, és preferible aquesta darrera opció, tenint en compte que sempre que el verb servir es combina amb un clític (24)-(26), aquest presenta cas acusatiu.

c. Dimats, a 29 de dit, a les quatre hores de la vesprada nostre Señor fonch servit de ploure. (Porcar, «Dietari», fol. 88v)

d. per a fer que lo cel fos servit de enviar la aygua, (Porcar, «Dietari», fol. I04v)

(ii) Déu se servixca de dar-nos pau ý quietut, per sa infinita bondat ý misericòrdia. (Porcar, «Dietar», fol. I99r)

a. Divendres, a II de febrer I606, vingué carta del señor rey que servís la vacant don Jaume Ferrer, governador. (Porcar, «Dietari», fol. I03r)

b. A 2I de dits se n'anà el bisbe Vives, de Sogorp, a servir son bisbat. (Aierdi, «Dietari», p. I82)

c. entrà en Sent Martí, a servir la vicaria per la ausència del vicari mosén Vicent Ferrer (Porcar, «Dietari», fol. $364 \mathrm{r}$ )

d. Ý un beneficiat de dita església, nomenat Sentapau, que en dit añy servia lo offici de racional (Porcar, «Dietari», fol. 5IOv)

e. Dimecres, a 2I de dehembre I605, dia de sent Thomàs, a les quatre hores de la vesprada entraren en processó los Lobregones per a servir lo Hospital. (Porcar, «Dietari», fol. Ioov)

IO. V. la nota anterior. 
(26) a. Ý si açò és com se adverava, molt nostre Señor lo tindrà de la sua mà, per a que acerte a servir-lo ý que governe bé. (Porcar, «Dietari», fol. I7ov)

b. Ý hallí [el nunci] dix missa en lo altar major. Servi.l lo comte de Bunyol de donar-li la tovalla, (Porcar, «Dietari», fol. 44Ir)

c. Respongueren obehirian a sa magestat $\mathrm{y} \cdot \mathrm{l}$ servirian en tot lo que fos just. (Pujades, «Dietari», fol. 225v)

d. A las quatre duenyas posaren en una taula a part y foren més ben servidas que sos amos (Pujades, «Dietari», fol. 228)

e. A lo qual la ciutat responia que era molt just que sa machestat quedàs servit, y que tots estaven promptes a servir-lo (Aierdi, «Dietari», p. 300)

(27) a. Perquè ultra que al rey, mon pare, servíreu extraordinàriament per dos vegades en breus dies, ý en cascuna ab cent mil ducats, a mi me haveu servit altres dos (Porcar, «Dietari», fol. 76v)

b. jurà per virey lo señor don Jaume Ferrer [...]. Ý esta fonch la quarta vegada que ha servit a Sa Magestat de virey, per les vaccants. (Porcar, «Dietari», fol. 233v)

c. Ý aquest gich estava dins per servir a son pare, (Porcar, «Dietari», fol. 247r)

d. Ý li havien fet moltes mercers ý moltíssimes més ne rebera, que no aspirava sinó ser benvolgut de tots ý servir a tot lo món, ab los diners que havia alcançat. (Porcar, «Dietari», fol. 262r)

e. cansat de servir a son amo. (Porcar, "Dietar», fol. 279r)

f. Crida sobre los béns dels qui servixen al rey (Porcar, «Dietar», fol. 38or)

g. Aquest dia se n'anava a servir al rey, (Porcar, «Dietar», fol. 466v)

h. perquè tenia gran habilitat ý havia servit a l'il.lustríssim duch de Segorb de tiple en sa joventut (Porcar, «Dietar», fol. 540r)

i. Y que a edat de 22 anys era anat a servir al rey en las jornadas contra los moros rebellats en Granada. (Pujades, «Dietar», fol. I63)

j. li vingué la mort per la casa de hont exia, perque servia de alcabot a la senyora y fou trait per lo matex marit. (Pujades, «Dietar», fol. 200v)

k. Dit dia se enbarcà Benet Vicent ab tota sa chent, per a Nàpols, a servir al rey per a eixir de treball (Aierdi, «Dietar», p. 258)

1. havien de anar a servir al rey per deixar la terra quieta; y es negocià en ells demanasen a este Ciurana per a que també anàs a servir al rey. (Aierdi, «Dietar», p. 267)

m. Dit dia se enbarcaren los Serveres, bandolers de la Ribera, per a anar a Nàpols a servir al rey per a eixir de treball. (Aierdi, «Dietar», p. 272)

n. tres anys a Nàpols a servir al rey per a poder eixir de treball (Aierdi, «Dietar», p. 272)

o. Y res de asò es cumplí, perquè se n’anà a Portugal a servir al rey. (Aierdi, «Dietar», p. 285)

p. Este fadrinet era de la Salsadella y servia a un llaurador que li deien Bartolo. (Aierdi, «Dietar», p. 298) 
Anna Pineda

Aspectes de la transitivitat en els inicis del català modern

\subsection{PRECEDIR, SEGUIR ${ }^{\mathrm{II}}$}

En el corpus estudiat tots els usos del verb precedir corresponen a sintagmes encapçalats per $a$ :

(28) a. se mogué alterca entre lo peblà de Ontiñent ý lo rector de Sant Martí sobre el puesto, pretenent avia de presehir lo peblà de Ontiñent a dit rector de Sant Martí ý als demés. (Antiquitats IV, p. 305)

b. Ý, axí, que dit peblà avia de presehir a dit rector de Sant Martí, (Antiquitats IV, p. 305)

c. Los doctors del real consell, càrrech per càrrech, pretenian que la canselleria havia de precehir a la Diputatió per ser més preminents los officials reals que los de la terra (Pujades, «Dietari», fol. II2v)

d. en lo qual los magnats de Catalunya precehiren al canseller y regent en los quals llavons concistia tot lo real Consell. (Pujades, «Dietari», fol. II6)

e. $Y$ en la taula precehiren los señors canonges que ixqueren en la embaxada a altres, encara que més antics (Antiquitats V, p. 329)

Tot i que els diccionaris descriptius $(D C V B)$ i normatius (DIEC2) només estableixen l'ús intransitiu d'aquest verb, és indicador que el $D C V B$ inclogui en la seva exemplificació fins a quatre usos del verb amb l'objecte introduït per a (la conversa que havia precedit al desma / precehim en nostre passatge a la illa / La perdiu precehix al conill / Es vist la conaxença sensitiva preceir a la intellectiva). Amb tot, l'absència d'exemples amb clítics, útils per desambiguar el cas dels complements, no permet aclarir si tots aquests exemples corresponen a objectes indirectes o bé a objectes directes amb MDO. Hem fet una cerca selectiva d'aquest verb més enllà dels límits del corpus establert, per constatar si en la resta dels textos analitzats, examinats sencers, hi havia

II. El verb succeir, semànticament similar, no presenta en canvi un règim vacil.lant, sinó que és consistentment intransitiu (v. $D C V B$, s.v. succeir i Pineda en prep.), encara que en la llengua actual no és estrany trobar-lo en construccions acusatives (com ja recull la nova Gramàtica de la llengua catalana (20I6: \$2I.3.4), malgrat el dictamen encara únicament intransitiu del DIEC2, s.v. succeir). En tot el corpus estudiat només en tenim dos exemples. En l'ocurrència de (i) el verb sembla adoptar més aviat la forma d'un substantiu deverbal. Interessa, però, que el complement és introduït per $a$, la qual cosa n'indica la naturalesa dativa. També sembla que cal analitzar com a datiu l'exemple de (ii):

(i) Y dit abbat li denuncià alguns béns en Igualada com a succehint a son germà don Jaime (qui era mort lo dia de Nadal), y tretze milı lliures en poder de dit abbat y quoranta mil al banc (Pujades, «Dietari», fol. 5I)

(ii) Dit dia don Pedro de Toledo, marques de Villafranca, embaxador per lo rey nostre senyor trames al de França per tractar casament entre lo príncep son fill y la filla primera del de Franca, y la segona de Espanya (perque no succehís Franca a Espanya) ab lo delfí de França (Pujades, «Dietari», fol. I24v) 
usos amb un complement singular pronominalitzat, que evidenciessin si el règim és sempre acusatiu (precedir-lo) o bé si hi ha casos de datiu (precedir-li). Efectivament, al costat de diversos exemples amb sintagmes, sempre precedits per $a$ (29), i al costat d'un exemple que indirectament reflecteix el règim transitiu del verb (30), el corpus ofereix també un exemple pronominalitzat que, justament, presenta cas datiu (3I), cosa que indica el règim vacil.lant transitiu/intransitiu del verb. En conclusió, no és possible determinar amb seguretat si cal considerar els exemples de (28) i (29) com a objectes directes amb MDO o com a objectes indirectes, i de fet trobem comportament variable d'aquest verb fins i tot dins d'una mateixa obra —en aquest sentit, l'estudi diacrònic de Pineda (en prep.), que abasta tot el període del català antic, serà revelador per acabar de definir l'evolució d'aquest verb.

(29) a. essent convidats los consellers de Barcelona y estant sentats ab ses cadires al altar major [...], don Phelip de Arill [...] se volgué assentar ab sa cadira al costat y precehir als consellers (Pujades, «Dietari», fol. I6I.)

b. Ý en lo primer lloch anava lo vicari Pere Llinares, home foraster ý de la Ribera, cosa que, per ser conforme sýnodo, és permés donar lloch a un home no beneficiat ý foraster, ý presedir a tan antichs beneficiats com y ha en dita església (Porcar, «Dietari», fol. 40or)

c. el bal.le, el governador y el mestre racional pretengueren asistir al mateix costat del virrey y en cadires, presehint a la Huniversitat, que estaven tots los que la componien y representaven seits en (Aierdi, «Dietari», p. 2I4)

(30) Y, per no estar lo governador, pretengué el bal.le ocupar lo puesto, en la Seu, del governador [...]. La ciutat digué que no perquè, presehint lo virrey [=subjecte], no podien estar presehits de altri que el governador, y que aquell tenia eixa preheminència per privilechi particular, y que dit bal.le no el tenia y, així, no li podia tocar lo puesto que pretenia. (Aierdi, «Dietari», p. 219)

(3I) Y tots estranyaren que la creu de la Seu anàs davant de totes les altres creus, y que totes li presedisen, sens saber la causa. (Aierdi, «Dietari», p. 4I2)

També en el cas de seguir els diccionaris són clars en establir l'ús transitiu amb complements de persona (v. DCVB, s.v. seguir, DIEC2, s.v. seguir). Efectivament, totes les ocurrències localitzades, moltes de les quals inclouen clítics de tercera persona, indiquen l'estabilitat de l'ús transitiu del verb — de nou, caldrà veure si es detecten usos clarament intransitius en l'etapa històrica precedent, v. Pineda (en prep.): ${ }^{12}$

I2. En canvi, el règim datiu caracteritza els usos del verb amb el significat 'ocórrer, passar': Al dit cavaller li segui que uns homes l'atacaren.

Caplletra 66 (Primavera, 2019), p. 207-236 
Anna Pineda

Aspectes de la transitivitat en els inicis del català modern

(32) a. Ý, donant-li lo cap del basto o bordó, lo va seguir, ý encontinent se trobà junt a Molvedre (Portés, p. 227)

b. ý lo punt mateix los digué que era en lo infern, ý que lo seguissen, que ell los ho amostraria; (Portés, p. 233)

c. Armers ab bandera de domàs blau ý atambors de guerra, ab dos hòmens armats seguint los atambors. (Porcar, «Dietari», fol. 9r)

d. Ý [subjecte: la reina] entrà ab sellò, a cavall [...]. Ý seguia-la sa mare a cavall en altre selló, ý aprés la duquesa de Gandia ab altre selló (Porcar, «Dietari», fol. 36r)

e. y hun de dits alcaydes digué al dit doctor que sa magestat manava que.s posàs en una carroça que allí hy havia y que.l seguís. (Pujades, «Dietari», fol. 50)

f. Lo bisbe y Capítol seguian la part del virey y real Consell. (Pujades, «Dietari», fol. II3)

\subsection{PLAURE}

Si bé en el català antic existia, en determinats registres literaris, un ús de plaure transitiu, parcialment reservat per a objectes inanimats i sovint abstractes (v. DCVB, s.v. plaure, p. ex. plaure la raó; i Pineda en prep.), el fet és que en el català de l'inici de l'etapa moderna no sembla que es preservi aquest ús. Totes les ocurrències que hem trobat en el nostre corpus corresponen a objectes referits a persones i introduïts per $a$ (33), fet que ens condueix a afirmar que es tracta del règim intransitiu més general del verb plaure — hem fet també una prospecció d'aquest verb més enllà dels límits establerts inicialment al corpus, amb l'objectiu de trobar exemples amb el complement singular pronominalitzat o bé exemples amb sintagmes no encapçalats per $a$, és a dir, exemples que poguessin evidenciar l'existència d'un ús transitiu, però la recerca ha estat infructuosa.

(33) a. Plàcia al Senyor sia a honra ý glòria sua, ý done perseverància que millor lo pugam servir. (Memorial V, p. IO2)

b. Jo estich molt cansat; demà, si plau a Déu, que serà dia de Sant Bertomeu, dia asenyalat, vos ó diré» (Portés, p. 229)

c. lo judici, si plau a Déu, no.l perdré, (Portés, p. 232)

d. confirmava altros privilegis vells de dita vila y deya plau a sa magestat confirmar-los si (Pujades, «Dietari», fol. Io9)

\subsection{PEGAR}

El règim variable del verb pegar (lipeguen, elpeguen), molt present en català actual, ha estat notat per diversos autors (v. p. ex. Cabré i Mateu I998: 70, n. II; Solà I994: 
I7I; Rosselló 2002: 1939; Pineda 2016: $\$$ 5). En canvi, tant el DCVB com el DIEC2 en recullen només l'ús intransitiu. És possible que sigui un canvi relativament recent — de nou, l'estudi diacrònic de Pineda (en prep.) podrà confirmar aquesta afirmació. De moment, constatem que en el corpus estudiat només hi ha tres ocurrències del verb, totes de la mateixa obra (un text valencià), i significativament dues presenten l'objecte pronominalitzat a través d'un clític datiu (34). Això condueix a pensar que molt probablement el sintagma de $(35)$ ha de ser interpretat també com un objecte indirecte, i no com un objecte directe amb MDO:

(34) a. Y a la velleta, que estava en lo llit, li pegaren en una culata de escopeta en lo cap y la deixaren per morta (Aierdi, «Dietari», p. I78)

b. Montalvan, avans de deixar-lo eixir de allí, davant de sos ulls, li pegaren de punyalades y el mataren. (Aierdi, «Dietari», p. I8I)

(35) Y tirant una escopetada, pasà la porta y pegà en los pits al que estava furgant per a obrir-la. (Aierdi, «Dietari», p. I77)

\subsection{ROBAR}

L'alternança acusatiu/datiu amb el verb robar és plenament vigent en la llengua actual, fins al punt que la recull el diccionari normatiu (DIEC2, s.v. robar). Com apunta Pineda (2016: $\$$ 5.2.4), les distincions que procura establir la normativa entre l'ús transitiu i l'intransitiu són molt subtils, però certament s'hi pot veure una lleugera diferència quant al grau d'afectació: l'ús intransitiu (li van robar) correspon a una menor afectació i és definit com a 'apropiar-se indegudament, amb violència, amb engany, d'amagat (allò que és propietat d'altri)'; en canvi, l'ús transitiu (el van robar) correspon a un significat que denota una major afectació, 'desposseir (algú) de les coses que li pertanyen, indegudament, amb violència, amb engany, d'amagat'. Coincidint amb el dictat de la normativa, el $D C V B$ (s.v. robar) estableix que només l'ús en què la víctima del robatori és un objecte directe correspon al significat de 'desposseir', que denota una major afectació (sobre aquesta noció, v. Pineda 20I6: $\$$ 5.6.2).

Aquest estat de coses provoca que, davant de l'ús de robar amb un sintagma introduït per $a$, l'anàlisi pugui correspondre tant a un ús transitiu com a un ús intransitiu del verb. Només l'avaluació acurada del context, per detectar-hi el grau d'afectació de la víctima, podria ajudar a fer decantar l'anàlisi cap a una de les dues opcions. Precisament, en el corpus estudiat ens trobem amb aquest dilema, perquè tenim tant ocurrències del verb clarament transitives (36) com d'altres que, aparent- 
Anna Pineda

Aspectes de la transitivitat en els inicis del català modern

ment, podrien ser casos d'objectes directes amb MDo o d'objectes indirectes (37). ${ }^{13}$ Totes les ocurrències pertanyen al mateix text, d'adscripció valenciana.

(36) a. y al chic, que estava en altre aposento chitat, perquè els conegué, el lligaren en una veta, lo ofegaren y robaren la casa. (Aierdi, «Dietari», p. I78)

b. Dona robada y morta per robar-la. (Aierdi, «Dietari», p. I79)

(37) a. Dona robada y morta per robar-la. A 4 de dits robaren a una dona y la mataren. (Aierdi, «Dietari», p. I79)

b. A 22 de dits, a la nit, volent robar al doctor Blasco, fill del doctor Blasco, a la plasa de Mosén Sorell, estant ya els lladres dins de casa y volent obrir una porta de uns entresuelos, eu sentí dit Blasco (Aierdi, «Dietari», p. I77)

Hi ha, però, diverses qüestions que ens poden ajudar a determinar si l'ús de robar de (37) correspon al règim transitiu o a l'intransitiu. Per començar, aquestes ocurrències pertanyen a la mateixa obra que les de (36), indiscutiblement transitives. A més, l'exemple robar a una dona de (37a) és de fet la continuació del «titular» que es donava en l'exemple (36b), la qual cosa ens condueix a pensar que es tracta d'un exemple de MDO. En el cas de (37b), en canvi, no podem descartar que el complement sigui un objecte indirecte, i que per tant el verb s'usi en el sentit, menys afectat, de 'prendre indegudament a algú (allò que li pertany)'. En aquest sentit, de ben segur que l'evolució del verb robar al llarg de tot el període del català antic (Pineda en prep.) serà il.lustrativa, i alhora permetrà dibuixar amb més seguretat com el català modern enllaça amb l'etapa actual, en què hi ha de manera clara una alternança acusatiu/datiu amb aquest verb (v. Pineda 2015, 2016).

\section{INTERACCIÓ ENTRE EL TIPUS DE CONSTRUCCIÓ I EL MARCATGE DIFERENCIAL D'OBJECTE}

En aquest apartat presentem diferents configuracions estructurals que tenen una incidència notable en el desencadenament del MDO. En algun cas, els diferents fenòmens que presentem aquí es poden produir conjuntament en una mateixa oració (per exemple, hi pot haver un objecte directe dislocat, que té un complement predicatiu i que a més forma part d'una estructura paral.lela amb elisió del verb); en tals

I3. Incloem en el recompte dels usos transitius clarament transitius un cas en què la víctima del robatori no és una persona, sinó un lloc. 
casos, hem considerat adequat classificar les oracions en qüestió com a exemples de cadascun dels diversos fenòmens.

\section{I DISLOCACIÓ}

El fet que les posicions dislocades dels objectes directes eren en la llengua antiga un factor desencadenant de la presència del MDO es desprèn, com bé apunta Sancho Cremades (2002: I738 i n. 67), dels treballs de Meier (I947, 1948), Rohlfs (I97I) i Perera (I986) (v. també Pineda en prep.). Efectivament, en l'estudi de corpus que hem dut a terme, la totalitat dels exemples d'aquest tipus presenten MDO:

(38) a. Ý la malaltia tan lo aquexava, al dit señor rey, que tingué contínua febra. (Porcar, «Dietari», fol. I3r)

b. Tornà-se-n a son aposiento, ý al marqués de Dénia, que.s diu don Francés de Royas ý de Sandoval, que era lo seu cavalleriz mayor, lo féu del Consell d'Estat [...] ý ad un Joan de Sandoval, son germà, primer cavalleriz dels quatres. (Porcar, «Dietari», fol. I4r)

c. dit Honorat Borja li seguí, que fonch a tan gran lo concurs de la gent en dita plaça de la Seu, que.l tornaren al dit Borja, ý a la sua cavalcadura, vint pases arrere. (Porcar, «Dietari», fol. 22r)

d. La ciutat de Valèntia donà dol a tots los de la Sala ý als consellers los vestiren de vajeta ý als offitials de la Sala drap ý raxa (Porcar, «Dietari», fol. 25r)

e. y els digué: «Fillets, dejau-lo confesar, per amor de Déu, a eixe pobret!» (Aierdi, «Dietari», p. 180)

\subsection{ALTRES QÜESTIONS D'ORDRE DE MOTS (ADJACÈNCIA AMB EL SUBJECTE)}

En alguns casos, l'ordre dels elements de l'oració pot ser un factor disparador del MDO, atès que hi ha una major necessitat de diferenciar el subjecte i l'objecte, tots dos postverbals — de fet, noteu que en els casos en què hi ha coincidència de nombre entre subjecte i objecte $\mathrm{i}$, per tant, la concordança verbal no és reveladora, el MDO permet desfer l'ambigüitat:

(39) a. \$Los officials de la Ciutat acompanyaren als señors justícies ý jurats de la Seu a la sala de la dita Ciutat, per no ser costum de acompanyar en aquest acte los jurats $a$ dit señor visrrey. (Antiquitats IV, p. 28I)

b. se mogué alterca entre lo peblà de Ontiñent ý lo rector de Sant Martí sobre el puesto, pretenent avia de presehir lo peblà de Ontiñent a dit rector de Sant Martí ý als demés. (Antiquitats IV, p. 305) 
Anna Pineda

Aspectes de la transitivitat en els inicis del català modern

c. A 4 de dits portaren en prosesó als catius que havia portat la redemció de la Mercé, y acompanyaven los frares de Sent Sebastià, los de Sent Agostí, los del Carme y els de Sent Domingo als frares de la Mercé. (Aierdi, «Dietari», p. I79)

d. En la plasa de la Seu esperava a nostra Senyora el Sentenar —el qual, al pasar, desparà-, les tres galeres y el carro triümphal, que fonch molt de veure. (Aierdi, «Dietari», p. 199)

e. Ý tocaren totes les parròchies de la present ciutat. Ý despertaren los escolans alsots_sacristà per a veure si tocarien a foch en lo campanar. (Antiquitats IV, p 274.)

$3 \cdot 3$ CONSTRUCCIONS CAUSATIVES (FER + INFINITIU) O AMB VERBS DE PERCEPCIÓ (VEURE, SENTIR + INFINITIU)

De manera general, en contextos causatius, el subjecte del verb seleccionat per fer és acusatiu si el verb és intransitiu (40), i datiu si el verb és transitiu (4I). El mateix val per als verbs de percepció veure, sentir, com observem en l'exemple amb un verb intransitiu i el seu subjecte en acusatiu (42):

(40) a. Alesores dit Pere Portés suplicà lo dexassen pujar [...] Alesmores digueren molts: I Edirectel «Dexen lo pujar, [...] Ý, rient, tots digueren: \Edirectel «Dexeu-lo acostar al hermari (Portés, p. 235)

b. anh allí y parla ab dit Vilanova descubrint-se ab-ell, penssant que lo Vilanova lo dexaria pendrer o almenys lo faria exir de sa casa. (Pujades, «Dietari», fol. II)

c. lo féu exir per una porta falsa de sa casa al dalt dit fossar del hospital (Pujades, «Dietari», fol. II)

d. Lo qual volgué que lo real consell en ninguna manera dexàs de anar, y digué que si dexava de anar que ell lo faria anar per força. (Pujades, «Dietari», fol. II3)

e. Y la Ciutat féu passar avant altre embaxador y fou Francesch Cosma Fivaller, cavaller, qui ya anava acompanyant al dit conseller. (Pujades, «Dietari», fol. II8v.)

f. Per lo qual hu de ells ixqué de la casa a buscar un confesor y, encontrant a mosén Juan Montalvan, el feren anar, dient que a una dona li havia pres un mal. (Aierdi, «Dietari», p. I80)

(4I) Añy 1560, a 28 de juny, los inquisidors anaren al Real ý allí feren als jurats, deputats ý staments, jurar los stabliments de la Inquisisió. (Porcar, «Dietari», fol. 2r.)

(42) Sentiren-se ullular y cridar los demonis per los ayres dient que morís la gent malvada que pecava a regna solta. (Pujades, «Dietari», fol. I07.)

Tanmateix, en el corpus estudiat hem observat que sovint quan el verb subordinat és intransitiu el seu subjecte, que és acusatiu, presenta MDo. Això ocorre tant en contextos amb el verb causatiu fer (43) com amb els verbs de percepció veure/sentir (45), que també seleccionen un infinitiu. 
(43) a. Ý tancaren lo portal del Real ab saques de llana ý ab moltes taules, ý feren entrar als frares del Remey dins ciutat. (Porcar, "Dietari», fol. 3v)

b. Ý lo il.lustríssim señor don fra Ysidoro Aliaga féu partir a dit lloch al doctor Pere Garcés, son vicari general (Antiquitats IV, p. 297)

En aquest altre cas, el pronom tots per se ja és un fort desencadenant de MDO:

(44) “¿Què te avem fet nosaltres, que ages tu gosat entrar assí, ý vulgas invocar [los] nom[s] de Jesús ý Maria, los quals nos fan tremolar a tots? (Portés, p. 227)

\subsection{PRESÈNCIA D'UN COMPLEMENT PREDICATIU REFERIT A L'OBJECTE DIRECTE}

Observem que la presència d'una predicació secundària (o complement predicatiu) sovint afavoreix la presència de MDo. En efecte, en la gran majoria de construccions amb un complement predicatiu referit a un objecte directe humà hi trobem el marcatge. En el corpus trobem exemples amb els verbs veure (45), deixar (46), fer (47), tenir (48), portar (49), posar (50), trobar (5I), nomenar (52), jurar (53) i consagrar (54): ${ }^{14}$

(45) per la mercé que Nostre Señor havia fet a aquesta ciutat ý regne en haver vist embarcats a tots los moros de aquell, (Antiquitats IV, p. 27I)

(46) a. ý que lo pare, quant morí, dexà hereu a son fillý li manà que restituís la heretat (Portés, p. 225)

b. Ý, ohint assò, encara tots se posaren a riure, en [tant] que se.n volían anar ý dexar $a$ dit Portés per loco. (Portés, p. 236)

c. Estigué.s tostemps, dit señor, ab gran sentit ý recort fins a micha hora ans que morís, que se li tancaren los ulls; dexant molt llastimats a tots los presents ý ausents, ab tanta falta ý mort. (Porcar, «Dietari», fol. I3v)

d. Vist assò, lo Vilanova apretà al Cisterer (a qui may havia dexat sol etiam dormint ab sa muller) y li posà cadena y $\mathrm{ab}$ un cotxe se.l ne tornà a cort. (Pujades, «Dietari», fol. $62 \mathrm{v}$ )

e. deixant governadora ý tutora del señor don Carlos segon a la señora reyna, sa mare, (Antiquitats V, p. 33I)

I4. També presenta MDo l'exemple de (i), també amb tenir, on a més l'objecte directe està dislocat. Però, de fet, cap d'aquests factors no és rellevant aquí, perquè el MDO és sistemàtic amb els pronoms personals ja des de finals del segle xv (v. Pineda en prep.):

(i) $A m$ i ja sé que me teniu per ignorant; (Portés, p. 232)

Caplletra 66 (Primavera, 2019), p. 207-236 
Anna Pineda

Aspectes de la transitivitat en els inicis del català modern

f. y tornaren a puchar en lo coche y se n'anaren, y deixaren a dit mosén Porcar nafrat, y al dematí morí. (Aierdi, «Dietari», p. I79)

(47) a. Tornà-se-n a son aposiento, ý al marqués de Dénia, que.s diu don Francés de Royas ý de Sandoval, que era lo seu cavalleriz mayor, lo féu del Consell d'Estat [...] ý ad un Joan de Sandoval, son germà, primer cavalleriz dels quatres. (Porcar, «Dietari», fol. I4r)

b. Ý a la vesprada féu del Consell d'Estat a Rodrigo Vàzquez Arze, son president de Castella. (Porcar, «Dietari», fol. I6r)

c. Diumenge, a 25 de abril, [el rei] féu del Tuson a l'archiduch, son cunyat, al duch de Tursis ý a l'almirant de Castella. (Porcar, «Dietari», fol. 38v)

(48) a. Ý era en tanta abundàntia la matèria que llançava de la cuxa, mà ý lloms, ý ab tanta patièntia ý suffriment, tenint per advocat al seu gran patró Llorens. (Porcar, «Dietari», fol. $\mathrm{I} 3 \mathrm{~V}$ )

b. A 22 de dits, dumenche, havent concedit la santedat de Alexandre Seté hun jubileu pleníssim, per quant lo Turch tenia molt apretat a l'emperador (Aierdi, «Dietari», p. 175)

(49) a. portant per patró o de sobrecarrech a Gabriel Marés, mariner de Barcelona, fou envestida alt a mar (Pujades, «Dietari», fol. I24v)

b. Y portaren pres a dit cavaller y no obstant que luego es sabé de sert, (Aierdi, «Dietari», p. I82)

c. Finalment, chamai se pogué averiguar per justícia, no obstant que después posaren preses a la muller de dit Leandro Escales y a sa filla, y estigueren anys preses, perquè la justícia sabia la veritat y no eu podia provar. (Aierdi, «Dietari», p. I82)

(5o) Posen presos a molts pobres estudiants perquè apedregaren lo palàcio del senyor arquebisbe. (Aierdi, «Dietari», p. I74)

(5I) a. A 5 de setembre I66I, trobaren un home mort y nuet en lo camí de Moncada, ab vinty-huit punyalades y una escopetada. (Aierdi, «Dietari», p. I79)

b. A I8 de dits trobaren, en lo mur del portal dels Jueus y de Ruçafa, mort a punyalades, al doctor Sabata, doctor en drets, en les mans lligades darrere y al coll, y vestit de negre. (Aierdi, «Dietari», p. I80)

(52) a. Ý dit rey nomenà en son confessor a fray Vicent Ferrer, predicador apostòlich. (Porcar, «Dietari», fol. Ir)

b. Martino V papa, añy I420, nomenà lo primer inquisidor de València a mestre Andreu Ros. (Porcar, «Dietari», fol. 2r)

c. lo il.lustre Capítol nomenà en comissaris per a la dita obra als señors canonges don Achilleo Figuerola, Josep Avellà, canonge doctoral, ý Melchor Fuster, canonge magistral, ý Cristòfol Marco, (Antiquitats V, p. 329)

(53) Añy I4I2, a 3 de setembre, juraren per rey de Aragó a don Ferrando, infant de Castella, en les Corts celebrades en Çaragoça los primers dies del mes de agost. (Porcar, «Dietari», fol. Ir)

(54) a. Diumenge, a I8 de octubre I598, consagraren en Morvedre a don Alonso d'Àvalos en bisbe de Coron. (Porcar, «Dietari», fol. I2r) 
b. Diumenge, a 28 de dit, consagraren en bisbes de Leyda a Francés Virgili, offitial de València, ý de Barcelona a don Alonso Coloma, canonge de Sevilla ý vissitador de l'Estudi de València. (Porcar, «Dietari», fol. I2v)

c. Diumenge, a I8 de octubre dit añy, I598, dia del gloriós sent Lluch, consegraren en Morvedre, en bisbe, al doctor Alonso d'Àvalos, vissitador general per lo patriarcha, bisbe de Coroni. (Porcar, «Dietari», fol. 26v)

d. Dijous a I5 estant tot lo que era necessari a punt per consagrar a fray [...] bisbe de Mallorcha y natural de aquella ciutat, frare de Predicadors, qui últimament era estat provincial en lo monastir de Santa Catherina martyr de Barcelona, (Pujades, «Dietari», fol. II5)

Així mateix, hi ha un grup d'exemples que tenen en comú el complement predicatiu, patent, combinat amb verbs diversos:

(55) a. Enaprés, per haver-se fet estes plegàries en la Seu, se continuaren en les parròquies y monestirs, tenint a nostre Senyor patent un dia, (Aierdi, «Dietari», p. I73)

b. A 7 de dits comensaren totes les parròquies, per son orde, a tenir un dia cada una, patent, a nostre Senyor, ab música y sermó cada dia. (Aierdi, «Dietari», p. 173)

c. Dit dia tragueren a nostre Senyor patent a l'altar machor, en la Seu (Aierdi, «Dietari», p. 172)

d. y luego descubriren patent a nostre Senyor. (Aierdi, «Dietari», p. 198)

També destaquem els dos casos següents, força inusitats per tractar-se de topònims (v. també Pineda en premsa: \$3.8):

(56) Dimecres, a I6 de setembre, a les 4 hores aprés migjorn, vingué molt gros lo riu, que sobrepujà a la venguda de l'añy 1589 , a 20 de octubre, que posà en gran admiració $a$ Valèntia. (Porcar, «Dietari», fol. 4r)

(57) A 22 de dits, dumenche, havent concedit la santedat de Alexandre Seté hun jubileu pleníssim, per quant lo Turch tenia molt apretat a l'emperador y a la república de Venècia, fonch publicat en la Seu, de matí, a la ora de l'offici, avans del sermó (Aierdi, «Dietari», p. 175)

En canvi, són molt menys nombrosos els exemples que no desencadenen MDo. El corpus ens n’ofereix els casos següents:

(58) a. advocat de la ciutat de Barcelona, anomenat Mosèn Ramon de la Freixeneda, lo qual per tenir plets ý donar consells tingué en vida molts hòmens pagats ý assalariats (Portés, p. 223) 
Anna Pineda

Aspectes de la transitivitat en els inicis del català modern

b. Dimarts a I4 vingué nova que lo rey de França té posats quoranta mil hòmens en campanya. (Porcar, «Dietari», fol. Io)

c. Ha fet marmessors los consellers cap y segon de Barcelona. (Pujades, "Dietari», fol 132)

d. A 13 de dits posaren presos molts estudiants pobres, dels que anaven per charitat al palàcio del senyor arquebisbe. (Aierdi, «Dietari», p. 174)

Noteu que la comparació de (58d) amb (50), ambdós exemples de la mateixa obra, permet concloure que el factor analitzat en aquest apartat, si bé és un desencadenant molt potent de MDO, pot produir resultats divergents fins i tot en oracions pràcticament idèntiques d'un mateix text.

\subsection{ESTRUCTURES COMPARATIVES O PARAL·LELES AMB VERB ELIDIT}

L'estudi de corpus que hem dut a terme ha revelat que els paral.lelismes o comparacions que impliquen l'elisió del verb afavoreixen molt notablement la presència de MDO (59). Totes les construccions d'aquest tipus que hem localitzat presenten, efectivament, el marcatge, llevat d'una (6o), que de fet presenta un objecte directe de característiques particulars, que pot ser interpretat més aviat com un inanimat ('el cos del sant') — v. més detalls sobre aquesta qüestió concreta en Pineda (en premsa: \$3.3):

(59) a. Diumenge, a 28 de dit, consagraren en bisbes de Leyda a Francés Virgili, offitial de València, ý de Barcelona a don Alonso Coloma, canonge de Sevilla ý vissitador de l'Estudi de València. (Porcar, "Dietari», fol. I2v)

b. Tornà-se-n a son aposiento, ý al marqués de Dénia, que.s diu don Francés de Royas ý de Sandoval, que era lo seu cavalleriz mayor, lo féu del Consell d'Estat --ý aprés fonch virey de Valèntia, en los añys I604 ý 5, ý·s jurà a 23 de febrer I604, a les 4 hores de la vesprada-- ý ad un Joan de Sandoval, son germà, primer cavalleriz dels quatres. (Porcar, «Dietari», fol I4r)

c. La ciutat de Valèntia donà dol a tots los de la Sala ý als consellers los vestiren de vajeta ý als offitials de la Sala drap ý raxa, ý sols vestiren al justítia criminal, que era March Antoni Gamir (Porcar, «Dietari», fol 25r)

d. diputats convidavan y graduavan cada any a la festa de sant Jordi als consellers y los consellers als diputats quant volian. (Pujades, «Dietari», fol. II2v )

(6o) Dit dia tragueren a nostre Senyor patent a l'altar machor, en la Seu, y a la una part de l'altar, fora, en una credència, a la mà dreta, posaren a nostra Senyora dels Desemparats, y a la altra part, de la mà esquerra lo gloriós sent Vicent Ferrer, ab sa relíquia. (Aierdi, «Dietari», p. I72) 


\subsection{LES PASSIVES PRONOMINALS}

Un darrer aspecte interessant dels textos analitzats és la presència de diverses ocurrències de $\mathrm{MDO}$ en el context de construccions passives pronominals, en concret pertanyents a una obra de la segona meitat del XVII, corresponent als parlars valencians. Aquestes construccions es caracteritzen, justament, per tenir un argument que normalment funciona com a subjecte i, per tant, concorda amb el verb (6I). Tanmateix, les propietats de subjecte d'aquest element (i.e., la concordança amb el verb) ja no es perceben si el nombre és singular (62). De fet, tant en plural com en singular, és possible que la llengua tracti l'argument nominal no com un subjecte sinó com un objecte directe (per a una visió detallada d'aquesta qüestió, v. Bartra 2002: \$I6.3.3). Això es traduirà en la manca de concordança, en el cas dels arguments plurals (63), i es podrà traduir, opcionalment, en la presència de MDO en el cas d'objectes directes que compleixin els requisits d'animacitat i definitud necessaris per al fenomen (64):

(6I) a. Es venen mobles de segona mà.

b. Es coronen molts reis.

(62) a. Es venen un moble de segona mà.

b. Es corona el rei.

(63) a. Es ven mobles de segona mà.

b. Es corona molts reis.

(64) a. Es corona a molts reis.

b. Es corona al rei.

Com avançàvem, la prospecció a la segona meitat del segle Xviı ens proporciona dos exemples d'aquest fenomen (65). Tots pertanyen a la mateixa obra, d'adscripció valenciana, en la qual hem trobat també tres exemples sense MDo (66). En canvi, en la resta d'obres del segle XviI, no hem trobat exemples d'aquestes construccions amb MDO, sinó que apareixen sense (67) —i pertanyen tant a l'àrea valenciana com a la del català central. Cal dir que, per fer el recompte, ens hem fixat en les passives pronominals amb un argument [+humà] susceptible de presentar tal marcatge.

(65) a. Y después, fent lo cambrer lo senyal, tancaren a nostre Senyor ab molta música, y después se tornà a nostre Senyor a la sua cappella, en processó, (Aierdi, «Dietari», p. 175)

b. En aver dinat se comensaren les vespres, a la una y micha, y después de dites se tancà a nostre Senyor y después se digueren les completes. (Aierdi, «Dietari», p. 198)

(66) a. Y per ser disapte es cantà la salve, es tancà el Santíssim, y esta vesprada assistí el virrey y la ciutat y el senyor arquebisbe. (Aierdi, «Dietari», p. I9I)

Caplletra 66 (Primavera, 2019), p. 207-236 
Anna Pineda

Aspectes de la transitivitat en els inicis del català modern

b. Baixà el senyor arquebisbe y es cantà una lletania ab molta solemnitat. Después, ab la mateixa música, es tancà nostre Senyor. (Aierdi, «Dietari», p. 192)

c. Deixaren-se en Senta Cathalina los sants ab les mateixes andes, arreglades en lo altar machor, chor y presbiteri. (Aierdi, «Dietari», p. I88)

(67) a. Nomenàs don Ferrando de Àustria (Antiquitats IV, p. 267)

b. Diumenge, a $\cdot X V I$. de octubre I6I6, [...] se consecrà en la present Seu lo reverendíssim señor don frare Phelip Guimerà, de la orde de Nostra Señora de la Merced (Antiquitats IV, p. 288)

c. Diumenge, a 9 de giner $1628,[\ldots]$ se consagrà en la present yglésia lo señor don Francisco López de Mendoza, canonge que fon de la Seu de València (Antiquitats IV, p. 294)

d. Ara se han presos dos hòmens en la matexa vila de Perpinyà (Pujades, «Dietari», fol. IOv)

e. Trobaren-se també en diversos llochs moltes persones mortes escalabrades, altres troçayades, y altres geladas del temor. (Pujades, «Dietari», fol. Io7v)

\section{ALTRES ASPECTES DE LA TRANSITIVITAT}

En aquest apartat final volem destacar un gir que apareix relativament sovint en la llengua antiga i que es preserva encara als inicis del català modern. Consisteix en la combinació de verbs de tipus intransitiu inergatiu, com riure o cridar, amb un objecte directe cognat (68), fenomen que trobem tant en textos del català central com valencians. En canvi, usos com el de (69) coincideixen més amb la llengua actual:

(68) a. Ý encontinent vegé passar dit Pere Portés davant de ell gran llegió de dimonis que ab una mà li donàvan bosses de diners foguejants de foch, ý ab altre li feyan les figues, rient grans riallades, quan deya, patint grans dolors ý horribles: \Edirectel «Teniu rahó; ja guanyarem,» (Portés, p. 223)

b. Però, perquè Pere Portés cridaba grans crits ý que en dit lloch era lo manual, resolgueren algunts, dient: (Portés, p. 236)

c. Ý per no haver-ne tengut notícia, del dit foch, per estar dormint, jatsia los orats cridaven molt grans crits, (Antiquitats IV, p. 274)

(69) Ý de la cayguda tractà mal a dos o tres fadrins, ý lo dit Borja cridant a grans crits, li accudí socorro dels caps de guaytes, (Porcar, «Dietari», fol. 22v)

Un altre aspecte que considerem interessant és l'ús transitiu causatiu (i.e. la causativització) de determinats verbs intransitius (70) — noteu que l'objecte directe en aquestes construccions no pot tenir característiques agentives, sinó que ha de ser una entitat inanimada (entrar el cotxe al garatge, pujar les caixes a l'altell) o bé, si és 
animada, mancada de voluntat, de capacitat de valdre's o de poder de decisió (entrar el malalt a l'habitació, pujar els nens a l'habitació) (v. Gràcia 1989: 86 i s.). Aquest fenomen és ben present en la llengua actual (Pineda 20r8), però en la llengua de l'etapa analitzada en trobem exemples fins i tot amb verbs que avui no ho permetrien (7I):

(70) a. Lancavan los malalts un fetor tant orrible que no y havia qui ls entràs en les cambres. (Pujades, «Dietari», fol. I22)

b. Ixqueren per la porta dels Apòstols y, prenint a nostra Senyora, la entraren per la porta del palau a l'altar machor. (Aierdi, «Dietari», p. 19I)

(7I) Dit dia, en la nit, en la plasa de la Seu mataren a escopetades a un vergueta, y a un aguasil li tiraren sinch escopetades y el corregueren per a matar-lo y escapà sinse ferir-lo. (Aierdi, «Dietari», p. I7I)

També trobem, en aquest sentit, alternances en un mateix text entre la causativització directa i la causativització a través de fer en el mateix fragment:

(72) Lo qual li fou enviat per dita Ciutat y axí scn torna. Y la Ciutat féu passar avant altre embaxador y fou Francesch Cosma Fivaller, cavaller, qui ya anava acompanyant al dit couseller. Lo matex orde reberen los embaxadors dels diputats y per 50 se'n tornaren los dos, y sols don Honofre de Aleutorn, ardiaca de Benasch, passà avant sa embaxada. (Pujades, «Dietari», fol. II8v.)

\section{CONCLUSIONS}

En aquest estudi de corpus hem volgut fer una primera aproximació a diversos aspectes de la transitivitat, entesa com a fenomen amb diversos vessants, en els textos corresponents a l'inici del català modern (segle XVII, amb un èmfasi especial en la primera meitat de segle). Hem tractat, concretament, el cas de diversos verbs que presenten un comportament vacil-lant entre l'ús transitiu i l'ús intransitiu, i ens hem acostat a aquest fenomen des del vessant del MDO, atès que aquest règim vacil.lant és un factor que pot crear confusió a l'hora d'analitzar l'extensió dels objectes directes introduïts per $a$ (v. $\$ 2$ ). A continuació, i encara mantenint el MDO com a punt de referència, ens hem fixat en les diverses construccions que afavoreixen notablement l'ús d'aquest marcatge davant dels objectes directes (v. $\$ 3$ ). Com dèiem a l'inici, el tractament d'aquests dos vessants del MDO s'ha d'entendre com un complement a l'estudi presentat en Pineda (en premsa), en què el fenomen era analitzat des de l'òptica de les característiques semàntiques dels objectes directes. Per acabar, hem 
tractat de manera succinta altres aspectes interessants de la transitivitat en els textos dels inicis del català modern, com ara l'ús de verbs inergatius en patrons transitius que inclouen un objecte directe cognat o la causativització de verbs intransitius que expressen moviment (v. $\$ 4)$.

\section{Anna Pineda \\ Universitat Pompeu Fabra anna.pineda@upf.edu ORCID 0000-0002-2810-9302}

\section{RELACIÓ D’OBRES DEL CORPUS ANALITZAT}

\section{Segle XVIIA}

Dietari de J. Pujades. I6o6-I6ro, Dietari de Jeroni Pujades. Edició a cura de Josep Maria Casas, Barcelona, Fundació Salvador Vives Casajuana, i975. [Clau de citació: Pujades, «Dietari».]

Dietari de P. J. Porcar. I589-I628, Lozano Lerma, Josep, «El dietari de Mossén Porcar (I585-I629). Estudi i edició», Universitat de València, tesi doctoral, 2008. [Clau de citació: Porcar, «Dietari».]

El 'Libre de Antiquitats' de la Seu de València 4. I604-I642, El Libre de Antiquitats de la Seu de València. Estudi i edició a cura de Joaquim Martí i Mestre, Barcelona / València, Publicacions de l'Abadia de Montserrat / Institut Interuniversitari de Filologia Valenciana, 1994, vol. I, p. 26I-325. [Clau de citació: Antiquitats IV.]

Un memorial de la guerra contra el turc 5. I600-1605, Vicent Ferrer $i$ Mayans, Un memorial de la guerra contra el turc, Barcelona, Curial, 1997. [Clau de citació: Memorial V.]

Viatge a l'infern d'en Pere Portés. I621?, "Viatge a l'infern d'en Pere Portes», Llegendes de l'altra vida. Edició a cura de R. Miquel i Planas, Barcelona, I9I4, p. 212-238. [Clau de citació: Portés]

Segle XVIIB

Dietari de J. Aierdi. I66I-I664, Aierdi, Joaquim, Dietari. Edició a cura de J. Vicent Escartí, Barcelona, Barcino, 1999. [Clau de citació: Aierdi, «Dietari».]

El 'Libre de Antiquitats' de la Seu de València 5. 1658-1679, El Libre de Antiquitats de la Seu de València. Estudi i edició a cura de Joaquim Martí i Mestre, Barcelona / 
València, Publicacions de l'Abadia de Montserrat / Institut Interuniversitari de Filologia Valenciana, I994, vol.I, p. 326-35I. [Clau de citació: Antiquitats V.]

\section{REFERÈNCIES BIBLIOGRÀFIQUES}

BARTRA, A. (2002) «La passiva i les construccions que s'hi relacionen», dins J. Solà, M.-R. Lloret, J. Mascaró \& M. Pérez Saldanya (ed.), Gramàtica del català contemporani, vol. 2. Barcelona, Empúries, p. 2III-2I79.

CABRÉ, T. \& J. MATEU (1998) «Estructura gramatical i normativa lingüística: a propòsit dels verbs psicològics en català», Quaderns. Revista de traducció, 2, p. 65-8I.

$D C V B=$ Diccionari català-valencià-balear, versió electrònica de l'obra originària d'Alcover i Moll. [<http://dcvb.iec.cat/>]

$D I E C_{2}=$ Diccionari de la llengua catalana, versió electrònica de la za edició. [<http:// dlc.iec.cat/>]

Gràcia, L. (1989) Els verbs ergatius en català, Maó, Institut d'Estudis Menorquins.

Gramàtica de la llengua catalana = INSTITUT D'ESTUDIs CATALANS (20I6) Gramàtica de la llengua catalana, Barcelona, Institut d'Estudis Catalans.

Meier, H. (I947) «O problema do acusativo preposicional no cataláo», Boletim de Filologia, 8, p. 237-260.

- (1948) Ensaios de filologia românica, Lisboa, Revista de Portugal

Morant, M. (2008) «L'alternancça datiu/acusatiu en la recció verbal catalana», tesi doctoral, Universitat de València.

Perera, J. (1986) «Contribució a l'estudi de les preposicions en el Tirant lo Blanch (Primera Part)», Llengua \& Literatura, I, p. 5I-IO9.

Pineda, A. (en prep.) «El complement directe», dins J. Martines \& M. Pérez-Saldanya (ed.), Gramàtica del català antic, Barcelona, Empúries.

- (en premsa) «Acostament al marcatge diferencial d'objecte als inicis del català modern", eHumanista.

- (20I5) «Del datiu a l'acusatiu. Un canvi sintàctic en procés en llengües romàniques i basc", Llengua \& Literatura, 25, p. 73-97.

- (2018) «Causativization of verbs of motion in Romance languages», dins P. Ordóńez \& L. Repetti (ed.), Romance Languages and Linguistic Theory. Selected Proceedings of the LSRL 46, Amsterdam/Philadelphia, John Benjamins, p. 245-262.

- (2016) Les fronteres de la (in)transitivitat. Estudi dels aplicatius en llengües romàniques i basc, Barcelona, Institut d'Estudis Món Juïc, Col-lecció Cum Laude, 6. 
Ramos, J. R. (2005) «El complement indirecte: l'alternança datiu/acusatiu», Estudis romànics / publicats a cura d'A. M. Badia i Margarit i Joan Veny, vol. 27, p. 94-III.

Rohlfs, G. (I97I) «Autour de l'accusatif prépositionnel dans les langues romanes», Revue de Linguistique Romane, 35, p. 312-334.

Rosselló, J. (2002) «El SV, I: Verb i arguments verbals», dins J. Solà, M.-R. Lloret, J. Mascaró \& M. Pérez Saldanya (ed.), Gramàtica del català contemporani, vol. II, Barcelona, Empúries, p. I853-1949.

SolÀ, J. (1994) Sintaxi normativa: estat de la qüestió, Barcelona, Empúries. 